\section{Tobacco, alcohol and drug use among dental undergraduates at one English university in 1998 and 2008}

\author{
B. Underwood, ${ }^{1}$ K. Fox ${ }^{2}$ and M. Manogue ${ }^{3}$
}

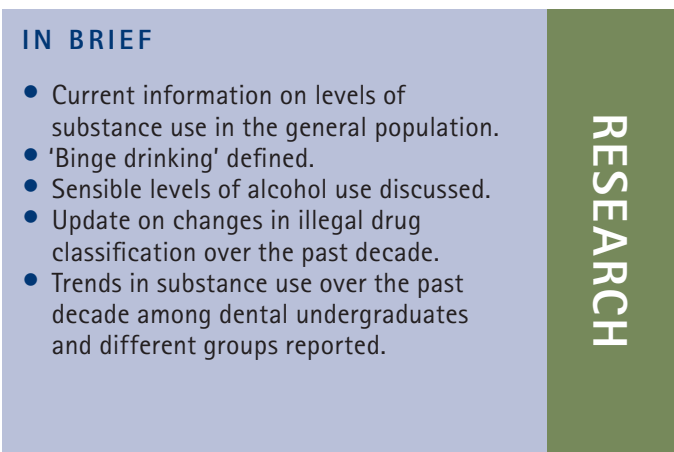

\begin{abstract}
Objective To estimate the prevalence of tobacco, alcohol and drug use among dental undergraduates at one English university in 2008, and compare these with prevalence in 1998. Design Cross-sectional survey using an anonymous self-report questionnaire. Subjects and methods In 2008 all 384 dental undergraduates at one English university were sent a questionnaire in order to obtain data on the frequency and amount of tobacco, alcohol, cannabis and other illicit drugs used before and during their time as a dental undergraduate. The same survey had been conducted on dental undergraduates at the university 10 years earlier. Results Tobacco smoking was reported by $27 \%$ of males and $13.5 \%$ of females, a reduction from 1998 ( $42 \%$ of males and 32\% of females) being significant among females. $63 \%$ of males and $69.5 \%$ of females reported drinking alcohol: significantly fewer than in 1998 ( $82 \%$ males and $90 \%$ females). Binge drinking was reported by $69.5 \%$ of males compared to $56 \%$ in 1998 . In females $66 \%$ binged compared to $58.5 \%$ in 1998. The increase in males was significant. $62 \%$ of males and $68 \%$ of females had never used cannabis compared to $38 \%$ in males and $50.5 \%$ of females in 1998, a significant reduction. A significant reduction in amphetamine use was reported among both male and female undergraduates in 2008 compared to 1998 and a significant increase in amyl nitrate use was reported by females. Reported illicit drug use was associated with alcohol drinking, and particularly with tobacco use. Conclusion Dental undergraduates at one English university in 2008 when compared to those in 1998 are reported to be significantly less likely to drink alcohol, use cannabis and amphetamines. If female, they are significantly less likely to smoke tobacco and overestimate the number of units of alcohol they can safely consume in a week, but more likely to use amyl nitrate. If male, those who drink alcohol are significantly less likely to drink at a level of increased risk, but more likely to binge drink.
\end{abstract}

\section{BACKGROUND}

In 1998 Underwood and Fox carried out a survey of tobacco, alcohol and drug use among all dental undergraduates at one English university. ${ }^{1}$ Undergraduates from all years $(\mathrm{n}=264)$ were questioned on their use of tobacco, alcohol, cannabis and other illicit drugs while at university and before entry. The study concluded that undergraduates at the university surveyed were 'drinking above sensible weekly limits, binge drinking and indulging in illicit

${ }_{1}$ GDP/Researcher, Clifton Moor Dental Centre, York, Y030 4RZ; ${ }^{2}$ Lecturer in Restorative Dentistry, University of Liverpool, Liverpool, L69 3BX; ${ }^{3}$ Director of Learning and Teaching, Leeds Dental Institute, Clarendon Way, Leeds, LS2 9LU

${ }^{*}$ Correspondence to: Mr B. Underwood Email: bfdunderwood@btopenworld.com

\section{Online article number E8}

Refereed Paper - Accepted 25 August 2009

DOI: 10.1038/sj.bdj.2010.183

"British Dental Journal 2010; 208: E8 drug use to a degree which may damage health and future careers'.

It is a decade since this original study was carried out and it is not known whether the trends in tobacco, alcohol and drug use observed in the general population, and other groups, have been mirrored in the dental undergraduate population.

\section{General population trends}

\section{Tobacco}

The Office for National Statistics (ONS) reporting on data from the General Household Survey (GHS) 2007 found the proportion of adults in the general population who smoked cigarettes fell substantially in the 1970s and the early 1980s, from 45\% in 1974 to 35\% in 1982. After 1982 it declined gradually until the early $1990 \mathrm{~s}$ where it levelled out. It then fell smoothly from $28 \%$ in $1998 / 99$ to $21 \%$ in $2007 .^{2}$

\section{Alcohol}

The ONS, reporting on data from the GHS 2006, found men drank an average of 14.8 units per week, about 2.5 units less than they were drinking between 1998 and 2002. Women drank an average of 6.2 units a week in 2006, a reduction of about 1.5 units from 2002, up to which a steady rise in consumption had been reported from 1998. ${ }^{3}$

The ONS Omnibus Survey 2007, ${ }^{4}$ reporting on average weekly alcohol consumption of different types of drink, found no significant changes between 1997 and 2007 in levels of consumption when using the 'original method' of estimating units of alcohol per drink. The 'original method', refers to the calculation the GHS surveys used before 2007 to convert respondents' reported alcohol consumption to units of alcohol, with the assumption that a 'glass of wine' contained one unit of alcohol. In 
2007 an 'updated method' was introduced which takes into account that in recent years the alcohol content of some drinks and the size of wine glasses used in pubs has increased. This has led to the updated assumption that one glass of wine now contains two units. The updated method when applied to the 2007 data gives an increase of 30\% overall in consumption, with men's average consumption increasing by $23 \%$ and women's by $45 \%$. The marked increase for women is due to the higher proportion of wine consumed.

\section{Binge drinking}

The term 'binge drinking' has no one clear definition..$^{5,6}$ This causes confusion and misunderstanding when studies using different definitions are compared. Gill ${ }^{7}$ observed seven different definitions of 'binge drinking' when reviewing studies that reported on alcohol consumption among undergraduates.

The GHS 2007 reported 24\% of men drank more than 8 units on at least one day in the previous week; this was higher than that reported in 1998 at 22\%. Among women, the increase was far greater from 8\% in 1998 to $15 \%$ in 2007 drinking over 6 units on at least one day in the previous week. ${ }^{2}$

\section{Drugs}

The reported use of cannabis by the general population ${ }^{8}$ has fallen from $10.3 \%$ in 1998 to $7.4 \%$ in 2007/08 for those who reported use in the year before interview. As cannabis is by far the most commonly used illicit drug, this has had a direct effect on reported use of 'any drug', with an observed reduction mirroring that of cannabis. Reported use of Class A drugs in the general population saw an increase from $2.7 \%$ in 1998 to 3.0\% in 2007/08, but this change was not significant. The rise has been mainly due to the increase in use of cocaine powder from $1.2 \%$ to $2.3 \%$ over the same period.

\section{Trends in young people}

\section{Tobacco}

The GHS 2007 reported a decline in smoking since 1974 in 16-19 year olds, with a prevalence of $22 \%$ being reported by young men and $20 \%$ by young women in 2007 compared to 30\% by young men and $32 \%$ by young women in $1998 .{ }^{2}$

\section{Alcohol}

The GHS 2006 reports the fall in alcohol consumption in the general population has been marked among those aged 16-24. The proportion of young men drinking more than 21 units a week fell from 41\% in 2000 to $26 \%$ in 2006 ; the respective fall in young women drinking over 14 units was from $33 \%$ to $19 \%{ }^{3}$

\section{Binge drinking}

Reported drinking of 'more than six units on at least one day in the previous week' by young women aged 16-24 saw a steady upward trend from $24 \%$ to $28 \%$ between 1998 and 2002. This has since fallen back to $24 \%$ in $2007,{ }^{2}$ even with the 'updated method' used to calculate units. The proportion of young men aged 16 to 24 drinking over eight units was little changed between 1998 and 2003 (1998: 39\%, 2003: $37 \%)$; however a fall was then recorded to $32 \%$ in 2007.2

\section{Drugs}

The reported use of cannabis by young adults aged 16-24 in the general population has fallen from $28.2 \%$ in 1998 to $17.9 \%$ in $2007 / 08 .^{8}$ As in the general population, cannabis is by far the most commonly used illicit drug by young people and this has had a direct effect on reported use of 'any drug', with a statistically significant reduction from $31.8 \%$ to $23.1 \%$ between 1998 and 2007/08 being seen. Reported use of Class A drugs by young adults has remained fairly stable between $1998(8.6 \%)$ and 2007/08 (6.8\%). ${ }^{8}$

\section{Trends among vocational dental practitioners (VDPs)}

The majority of VDPs are newly qualified dental graduates, who must complete one year of vocational training (VT) before they can be allocated dental list numbers by a primary care trust, enabling them to work in the general dental services and personal dental services. ${ }^{9}$ The majority of graduates commence VT in July/August of the year they qualify. Underwood et al. carried out a survey of all UK VDPs' tobacco, alcohol and drug use in $2000^{10}(\mathrm{n}=502)$, with a repeat in $2005(n=534) .{ }^{11}$

\section{Tobacco}

Regular tobacco use ( $\geq 10$ cigarettes per day) by VDPs was reported by $5.4 \%$ of males and $4.0 \%$ of females in 2005. This was lower than reported by both sexes in $2000(9 \%)$ and a significant reduction in males. ${ }^{11}$

\section{Alcohol}

Eighty-two percent of males and $81 \%$ of females reported alcohol use, significant reductions from 2000 (89\% males and $88 \%$ females). ${ }^{11}$

\section{Binge drinking}

Binge drinking ( $\geq 10$ units for males and $\geq 7$ units for females in average drinking session) was reported by $44 \%$ of male and $39 \%$ of female VDPs who drank alcohol in 2005, similar to levels reported in $2000 .^{11}$

\section{Drugs}

Thirty-eight percent of males and 26\% of females reported cannabis use during their VT, similar to levels seen in 2000. Reported use of illicit drugs in 2005, other than cannabis, was less than in 2000.11

\section{Trends among non-dental undergraduates}

There is currently no published information on trends in tobacco, alcohol and drug use among non-dental undergraduates in the UK over the past decade. The results of this study may give some indication of trends in the wider undergraduate population. A cross-sectional survey carried out in 2001 comparing substance use among dental and law undergraduates ${ }^{12}$ reported that dental undergraduates appeared to be indulging in similar levels of alcohol and illicit drug use as law undergraduates, but were significantly less likely to smoke tobacco.

Unhealthy patterns of tobacco, alcohol and drug use developed as a dental undergraduate may well continue after graduation $^{13}$ and have serious consequences for an individual's professional future and general well-being. Further, it is important to protect the public who may receive poor treatment as a result of alcohol and drug use by an undergraduate or qualified dentist.

The aims of this study were to survey all dental undergraduates at one English university in 2008 in order to ascertain their tobacco, alcohol and drug use during and before becoming an undergraduate. It 
shows how tobacco, alcohol and drug use has changed since 1998 when the survey was first carried out, helping to identify trends in use among dental undergraduates at one English university.

\section{METHOD}

A cross-sectional survey of all dental undergraduates studying in years 1 to 5 at one English university $(\mathrm{n}=384)$ in 2008 was conducted, repeating a survey carried out by the lead author 10 years earlier at the same university.

The questionnaire used (copy available from the corresponding author) requested information on the frequency of tobacco smoking, alcohol and illicit drugs use while an undergraduate and before becoming an undergraduate. The questionnaire was distributed to 2nd, 3rd and 4th year students before scheduled lectures. Absentees, 1st and 5th year students were contacted via internal mail. This matches the method of distribution used in 1998.

Three updates were made to the questionnaire used in 1998. Firstly, due to recent suggested increases in the use of anabolic steroids ${ }^{14}$ among under-25-year-olds in the general population, a question on anabolic steroid use was added. Secondly, the guidelines given to students on how many units of alcohol different drinks contain was updated. In 1998 a glass of wine was given as containing 1 unit:

- 1 pint strong beer/lager $=3$ units

- 1 pint normal beer/lager $=2$ units

- 1 bottle alcopop = 2 units

- 1 glass wine $=1$ unit

- 1 measure of spirits $=1$ unit.

In the 2008 questionnaire this was increased to 2 units:

- 1 pint strong beer/lager $=3$ units

- 1 pint normal beer/lager $=2$ units

- 1 bottle alcopop = 2 units

- 1 glass wine $=2$ units

- 1 measure of spirits = 1 unit.

This reflects the increase in size of the average glass used in pubs and also the increased strength of wine since 1998. Similar increases have been used on the latest GHS ${ }^{4}$ and Omnibus ${ }^{5}$ surveys. Thirdly, to comply with updated ethical approval guidelines, students were given an information sheet to keep for future reference.

Table 1 Tobacco smoking reported by dental undergraduates in 1998 and 2008

\begin{tabular}{l|l|l|l|l|} 
& \multicolumn{2}{|l}{ Males } & Females \\
\cline { 2 - 5 } & $\begin{array}{l}\text { Smoking* } \\
\%(n)\end{array}$ & $\begin{array}{l}\text { Current** regular } \\
\%(n)\end{array}$ & $\begin{array}{l}\text { Smoking } \\
\%(n)\end{array}$ & $\begin{array}{l}\text { Current regular } \\
\%(n)\end{array}$ \\
\hline 1998 & $42.4(37 / 87)$ & $10.3(9 / 87)$ & $32.3(36 / 112)$ & $5.4(6 / 112)$ \\
\hline $\mathbf{2 0 0 8}$ & $26.9(25 / 93)$ & $4.3(4 / 93)$ & $13.5(22 / 161)$ & $4.3(7 / 161)$ \\
\hline Difference & 15.5 & 6 & 16.4 & 1.1 \\
\hline p-value & 0.123 & 0.146 & 0.003 & 0.714 \\
\hline
\end{tabular}

This was not necessary in 1998, when the front cover of the questionnaire gave the information.

Participants were provided with a free pen to act as an incentive to respond and increase anonymity. As in 1998, those completing the questionnaire in lecture theatres were spaced out from their peers in order to enhance confidentiality, thereby hopefully increasing the honesty of responses. For those contacted via internal mail, return of completed questionnaires was via a self-seal envelope giving the location of a sealed respondents' box, which was placed in the same location as in 1998. Those surveyed in lectures were asked to seal questionnaires in an envelope and place them in a sealed box in the lecture theatre.

As in 1998, anonymity of participants was essential and therefore no name, age or ethnic origin was requested.

The questionnaire was administered over a three-week period from 19 May 2008 to 5 June 2008. This is the same start date used in 1998, but one week longer due to 2 nd year students being unavailable for 2 weeks due to clinical commitments.

Statistical analysis was carried out using SPSS 16 . Results are mainly descriptive. The chi-squared test was used to make comparisons between 1998 and 2008.

\section{Ethical approval}

Ethical approval was obtained from the relevant Local Educational Research Ethics Committee. Approval from the Dean of the Dental School was given. Approval was also given by the Regional Postgraduate Dental Dean and the General Dental Council was consulted.

\section{RESULTS}

Questionnaires were returned by 265 undergraduates out of a possible 384 (69\%). Of these, 4 respondents did not wish to complete the questionnaire and 3 were spoilt. This gave a usable response rate of $67 \%$ ( $\mathrm{n}=258$, male response rate $93 / 157=64 \%$, female response rate $165 / 227=73 \%$ ). In 1998 a usable response rate of $76 \%$ was achieved, with 200 undergraduates out of 264 responding (male response rate 88/121 $=73 \%$, female response rate $112 / 143=78 \%$ ).

\section{Tobacco smoking}

The prevalence of tobacco smoking by undergraduates (defined as those who smoke only while drinking alcohol or with cannabis or those who smoked $\geq 10$ cigarettes per day at any point during their time as an undergraduate) was 26.9\% for males and 13.5\% for females in 2008. This is a reduction from 1998 when 42.4\% of males and $32.3 \%$ of females reported smoking tobacco. This reduction was significant among females ( $p=0.003$ ), but not males (Table 1).

In 2008, current tobacco smoking of $\geq 10$ cigarettes per day was reported by $4.3 \%$ of both sexes compared to $10.3 \%$ of males and 5.4\% of females in 1998. This reduction was not significant.

There had also been a reduction in tobacco smoking reported before becoming a dental undergraduate, with 56.5\% of undergraduates having never smoked tobacco in 2008 and 41\% in 1998. This was not significant $(p=0.051)$.

\section{Alcohol}

The prevalence of undergraduates reporting drinking alcohol in 2008 was 63.4\% 
of males and 69.5\% of females (Table 2): significantly fewer undergraduates than in 1998 at $81.8 \%$ of males and $90.2 \%$ of females ( $\mathrm{p} \leq 0.006$ ).

Table 3 shows the detailed results on alcohol intake and knowledge of those undergraduates who drank alcohol according to gender. In 2008, fewer undergraduates drank above sensible levels in the week before being surveyed when compared to undergraduates in 1998. Of male undergraduates in 2008, 23.7\% were drinking alcohol at a level which was likely to increase their risk of health problems and $1.7 \%$ were drinking at a level hazardous to health. This compares to $50.7 \%$ and $12.7 \%$ for males in 1998. However, only the reduction in drinking at an increased level was significant ( $p=0.016$ ).

Among females there was also a reduction in drinking alcohol at a level of increased risk or hazardous to health (2008: increased risk 31.3\%, hazardous 2.6\% and 1998: increased risk 35\%, hazardous 7\%). These reductions were not significant.

Binge drinking (defined as $\geq 10$ units for males and $\geq 7$ units for females in an average drinking session) increased in prevalence in 2008 compared to 1998 , with $69.5 \%$ of males in 2008 bingeing on an average drinking session compared to 55.6\% in 1998. In females the increase was to $66.1 \%$ in 2008 from $58.5 \%$ in 1998 . Only the increase in males was significant $(\mathrm{p}=0.011)$.

Fewer undergraduates who drank in 2008 overestimated the safe weekly maximum number of units they could consume. Only 15.3\% of males in 2008 thought they could safely consume over 21 units in a week compared to $30.6 \%$ in 1998 . Among females, $11.4 \%$ thought they could consume more than 14 units in 2008 compared to $29.6 \%$ in 1998 . The increase in the number of undergraduates knowing their safe weekly limits was significant for females ( $p=0.002$ ) but not for males.

Weekly consumption of alcohol before becoming a dental undergraduate was reported as less by the majority of both male and female undergraduates who drank (Table 2). This finding had not significantly changed between 1998 and 2008.

\section{Cannabis}

There was a significant reduction in the number of both male and female undergraduates ( $p<0.001)$ who reported cannabis
Table 2 Alcohol use reported as a dental undergraduate and before entry to university in 1998 and 2008

Survey question

\begin{tabular}{|l|l|l|l|l|}
\multicolumn{2}{l|}{} & \multicolumn{3}{|l|}{ Males } \\
\cline { 2 - 6 } & $\begin{array}{l}1998 \\
\%\end{array}$ & $\begin{array}{l}2008 \\
\%\end{array}$ & $\begin{array}{l}1998 \\
\%\end{array}$ & $\begin{array}{l}2008 \\
\%\end{array}$ \\
\hline Do you drink alcohol? & & & & \\
\hline Yes & $81.8^{*}$ & $63.4^{*}$ & $90.2^{*}$ & $69.5^{*}$ \\
\hline No & $18.2^{*}$ & $36.6^{*}$ & $9.8^{*}$ & $30.5^{*}$ \\
\hline
\end{tabular}

Did you drink alcohol before becoming a dental undergraduate?

\begin{tabular}{l|l|l|l|l|l|}
\hline Yes & $85.2^{*}$ & $64.1^{*}$ & $88.4^{*}$ & $70.1^{*}$ \\
\hline No & $14.8^{*}$ & $35.9^{*}$ & $11.6^{*}$ & $29.9^{*}$ \\
\hline
\end{tabular}

Do you think your average weekly consumption before becoming a dental undergraduate was...

\begin{tabular}{l|l|l|l|l}
\hline More & 20.8 & 13.8 & 5.1 & 12.1 \\
\hline Less & 68.1 & 67.2 & 73.5 & 67.2 \\
\hline No different & 11.1 & 19.0 & 21.4 & 19.8 \\
\hline Don't know & 0.0 & 0.0 & 0.0 & 0.9 \\
\hline
\end{tabular}

*Statistically significant difference between 1998 and 2008 p $\leq 0.006$

Table 3 Level of alcohol consumption and knowledge of safe drinking limits reported by dental undergraduates who consume alcohol in 1998 and 2008

\begin{tabular}{|c|c|c|c|c|}
\hline & \multicolumn{2}{|l|}{ Males } & \multicolumn{2}{|l|}{ Females } \\
\hline & $\begin{array}{l}1998 \\
(n=72) \\
\%\end{array}$ & $\begin{array}{l}2008 \\
(n=59) \\
\%\end{array}$ & $\begin{array}{l}1998 \\
(n=101) \\
\%\end{array}$ & $\begin{array}{l}2008 \\
(n=114) \\
\%\end{array}$ \\
\hline \multicolumn{5}{|c|}{ Alcohol consumption last week } \\
\hline Sensible & 36.6 & 74.6 & 58.0 & 66.1 \\
\hline Increased & $50.7^{*}$ & $23.7^{*}$ & 35.0 & 31.3 \\
\hline Hazardous & 12.7 & 1.7 & 7.0 & 2.6 \\
\hline \multicolumn{5}{|c|}{ Alcohol consumption during an average week } \\
\hline Sensible & 56.4 & 56.1 & 69.7 & 72.3 \\
\hline Increased & 39.5 & 43.9 & 30.3 & 25.0 \\
\hline Hazardous & 4.2 & 0.0 & 0.0 & 2.7 \\
\hline \multicolumn{5}{|c|}{ Alcohol consumption during an average drinking session ( $\left.{ }^{\ddagger} B i n g e\right)$} \\
\hline $1-6$ units & $6.9^{*}$ & $15.3^{*}$ & 41.4 & 33.9 \\
\hline $7-9$ units & $37.5^{*}$ & $15.3^{*}$ & ${ }^{\ddagger} 34.3$ & ${ }^{\ddagger} 42.0$ \\
\hline$\geq 10$ units & ${ }^{*} 55.6^{*}$ & ${ }^{*} 69.5^{*}$ & ${ }^{\ddagger} 24.2$ & ${ }^{\ddagger} 24.1$ \\
\hline \multicolumn{5}{|c|}{ Estimate of safe weekly maximum } \\
\hline $0-7$ units & 6.9 & 8.5 & 25.5 & 24.6 \\
\hline 14 units & 15.3 & 27.1 & 44.9 & 64.0 \\
\hline 21 units & 47.2 & 49.2 & 25.5 & 7.0 \\
\hline 28 units & 19.4 & 10.2 & 4.1 & 3.5 \\
\hline$\geq 35$ units & 11.2 & 5.1 & 0.0 & 0.9 \\
\hline \multicolumn{5}{|c|}{$\begin{array}{l}\text { Sensible level of alcohol consumption/week = 0-21 units males, 0-14 females } \\
\text { Increased risk level of alcohol consumption/week = 22-49 units male, } 15-35 \text { female } \\
\text { Hazardous to health level of alcohol consumption/week } 250 \text { units male, } 236 \text { female } \\
\text { Safe weekly maximum }=21 \text { units for males and } 14 \text { units for females } \\
\text { *Statistically significant difference between } 1998 \text { and } 2008 \text { p s0.016 }\end{array}$} \\
\hline
\end{tabular}




\begin{tabular}{|c|c|c|c|c|}
\hline & \multicolumn{2}{|l|}{ Males } & \multicolumn{2}{|l|}{ Females } \\
\hline & $\begin{array}{l}1998 \\
(n=87) \\
\%\end{array}$ & $\begin{array}{l}2008 \\
(n=92) \\
\%\end{array}$ & $\begin{array}{l}1998 \\
(\mathrm{n}=111) \\
\%\end{array}$ & $\begin{array}{l}2008 \\
(n=164 \\
\%\end{array}$ \\
\hline Never used & $37.9^{* *}$ & $62.0^{* *}$ & $50.5^{* *}$ & $67.7^{* *}$ \\
\hline Used once or twice & 18.4 & 16.3 & 23.4 & 22.0 \\
\hline Used more than one or twice & 25.3 & 14.1 & 11.7 & 6.7 \\
\hline Regular* user as undergraduate, but not now & $10.3^{* *}$ & $2.2^{* *}$ & $8.1^{* *}$ & $3.0^{* *}$ \\
\hline Current regular* user & $8.0^{* *}$ & $5.4^{* *}$ & $6.1^{* *}$ & $0.6^{* *}$ \\
\hline
\end{tabular}

Table 5 Reported illicit drug use (including amyl nitrate and inhalants which are not classified as illegal to use) whilst a dental undergraduate in 1998 and 2008

\begin{tabular}{|c|c|c|c|c|c|c|c|c|}
\hline & \multicolumn{4}{|l|}{ Males } & \multicolumn{4}{|c|}{ Females } \\
\hline & \multicolumn{2}{|c|}{ Ever tried \% } & \multicolumn{2}{|c|}{ Regular user \% } & \multicolumn{2}{|c|}{ Ever user \% } & \multicolumn{2}{|c|}{ Regular user \% } \\
\hline & 1998 & 2008 & 1998 & 2008 & 1998 & 2008 & 1998 & 2008 \\
\hline Amphetamine & 12.6 & 6.7 & 6.8 & 2.2 & 8.1 & 5.5 & 4.5 & 0.0 \\
\hline LSD & 8.0 & 4.4 & 1.1 & 0.0 & 1.8 & 1.2 & 0.0 & 0.0 \\
\hline Ecstasy & 6.9 & 10.0 & 2.3 & 1.1 & 4.5 & 5.5 & 1.8 & 1.2 \\
\hline Cocaine & 3.4 & 8.8 & 2.3 & 3.3 & 1.8 & 4.9 & 1.8 & 0.0 \\
\hline Amyl Nitrate & 13.7 & 13.4 & 2.2 & 3.3 & 10.8 & 20.1 & 0.0 & 0.6 \\
\hline Inhalants & 4.5 & 3.3 & 1.1 & 0.0 & 0.0 & 1.2 & 0.0 & 0.0 \\
\hline Magic mushroom & 8.0 & 6.6 & 1.1 & 2.2 & 6.3 & 4.2 & 0.0 & 1.2 \\
\hline Anabolic steroids & $\mathrm{n} / \mathrm{a}$ & 0.0 & $n / a$ & 1.1 & $n / a$ & 0.0 & $n / a$ & 0.6 \\
\hline No. of undergraduates & 88 & 90 & 88 & 90 & 111 & 164 & 111 & 164 \\
\hline
\end{tabular}

Table 6 The association between drug use, tobacco smoking and alcohol drinking

\begin{tabular}{|l|l|l|l|l|}
\hline & $\begin{array}{l}\text { No alcohol and } \\
\text { never smoked }\end{array}$ & $\begin{array}{l}\text { Smokes* but does } \\
\text { not drink alcohol }\end{array}$ & $\begin{array}{l}\text { Alcohol drinker but } \\
\text { does not smoke }\end{array}$ & $\begin{array}{l}\text { Both smoker* } \\
\text { and drinker }\end{array}$ \\
\hline $\begin{array}{l}\text { Any drug used at } \\
\text { any time }\end{array}$ & $3 \%(2 / 62)$ & $30 \%(7 / 23)$ & $24 \%(17 / 71)$ & $68 \%(69 / 102)$ \\
\hline $\begin{array}{l}\text { Relative risk of drug } \\
\text { use (95\% Cl) }\end{array}$ & 1.0 & $\begin{array}{l}9.4 \\
(2.1-42.2)\end{array}$ & $\begin{array}{l}7.4 \\
(1.8-30.9)\end{array}$ & $\begin{array}{l}20.9 \\
(5.3-82.5)\end{array}$ \\
\hline \begin{tabular}{l} 
*Current or ex-smoker \\
\hline
\end{tabular} & & & \\
\hline
\end{tabular}

use while an undergraduate (Table 4). In $2008,62 \%$ of males and $67.7 \%$ of females had never used cannabis compared to $37.9 \%$ in males and $50.5 \%$ of females in 1998.

There was also a significant reduction ( $p<0.001$ ) in the number of male and female undergraduates who reported regular cannabis use (use at least once a
The number of undergraduates who had smoked cannabis before becoming a dental undergraduate was significantly lower in 2008 than 1998 ( $p=0.003)$.

\section{Other illicit drugs, amyl nitrate and inhalants}

Table 5 shows the detailed results of illicit drug use excluding cannabis (including amyl nitrate ${ }^{15}$ and inhalants ${ }^{16}$ which are not classified as illegal to use) among dental undergraduates in 2008 when compared to 1998.

In 2008 there was a reduction in the percentage of undergraduates reporting having been a 'regular user' (an undergraduate who has taken the substance at least once a month at any time while an undergraduate) or 'ever tried' (an undergraduate who used the substance once or twice or more than once or twice, but not on a regular basis at any time while at university) amphetamines or LSD when compared to 1998. This decrease was statistically significant for amphetamines ( $p=0.036$ for females and $p=0.042$ for males). An increase was seen in the percentage reporting having ever tried ecstasy or cocaine although this was not significant. A significant increase among female undergraduates having ever used amyl nitrate was reported, in 1998 this was $10.8 \%$ and in 2008 it was $20.1 \%$ ( $\mathrm{p}=0.031$ ).

Regular use of anabolic steroids (use at least once a month at any time as an undergraduate) was reported by $1.1 \%$ of male and $0.6 \%$ of female undergraduates in 2008. No comparison could be made with 1998 as use of this drug was not questioned then.

\section{Associations}

Reported illicit drug use was associated with drinking alcohol and smoking tobacco (Table 6). An undergraduate who reported drinking but did not smoke was 7.4 times more likely to have used any illicit drug compared to someone who neither drank nor smoked; someone who smoked but did not drink was 9.4 times more likely to have used illicit drugs. However, an undergraduate who both drank and smoked tobacco was 20.9 times more likely to use drugs, though note should be made of the wide 95\% confidence interval. 


\section{DISCUSSION}

This paper reports on tobacco, alcohol and illicit drug use among dental undergraduates at one English university before admission and during their studies in 1998 and 2008.

It is important before discussing the results of this to study to highlight its limitations. An assumption has to be made that the $33 \%$ of undergraduates who did not respond in 2008 are similar in terms of their use of substances to the $24 \%$ of undergraduates who did not respond in 1998. Further, it has to be assumed that those undergraduates who did respond were no more or less honest in their responses in 2008 than those in 1998.

As cautioned in the authors' VDP ${ }^{10,11}$ and $1998^{1}$ undergraduate studies, it would be inadvisable to compare the figures reported in this study with studies of substance use in the general population due to the lack of uniformity in methodologies and definitions of usage. However, trends can be compared with those in the general population. Comparisons between this study and the authors' VDP surveys can be made due to similar methodologies, but it should be noted these surveys were carried out in $2000^{10}$ and 2005. ${ }^{11}$

The dental undergraduates from the one English university surveyed may not be representative of all dental undergraduates at English or UK universities in the substances they use or patterns of use. Various studies of undergraduates have reported higher abstention rates from alcohol consumption, and less cannabis and tobacco use by ethnic minority students compared to white students. ${ }^{17,18}$ Tobacco and alcohol use in the general population also varies with ethnic origin. ${ }^{19}$ It was noted in the $1998^{1}$ study that the dental school surveyed had a higher ratio of ethnic minority undergraduates than would be found in the general population. In 1998 approximately 23\% of dental undergraduates at the school surveyed were from ethnic minorities, in 2008 this figure had increased to $46 \% .^{20}$ Further, the number of mature students (age 21 years or above) had increased from approximately $2 \%$ to $7 \%$.

This study cannot state why changes noted in substance use among dental undergraduates at the university have occurred as questions were not asked that elucidate this information. This is an area where further research is required.

The questionnaire used in this study does not differentiate between how a substance was used by an undergraduate, for example cannabis can be smoked or eaten, or whether cocaine was in powder form or as 'crack'. These different methods of use and preparations of a drug have different associated risks.

The effect of updating the questionnaire's guidelines to undergraduates on the number of units a glass of wine contains, from one in 1998 to two in 2008, cannot be analysed because respondents were not asked to separate out the different types of drinks they consume when reporting their alcohol consumption.

This study gives a snapshot view of substance use in 1998 and 2008; it should not be assumed that the changes seen in the substances being used by undergraduates has been linear over the 10 years. There may have been peaks and troughs in the use of each substance over the decade.

It cannot be demonstrated if the tobacco use, alcohol consumption above sensible levels and/or use of illicit drugs reported by undergraduates has resulted in any reduction in care they give their patients.

Recall bias maybe a problem when answering questions about substance use before becoming a dental undergraduate but as long as this is similar for both years this should not be of concern when looking at trends in use.

While this study has a number of limitations as mentioned above, what matters most is that the questionnaire was administered in a consistent manner in 1998 and 2008 , at the same time of year, in the same conditions and achieving a high response rate, making its finding relevant to the evidence base.

A usable response rate of $67 \%$ was achieved in 2008 ( $n=258)$, compared to $76 \%$ in $1998(\mathrm{n}=200)$. The lesser response rate in 2008 is disappointing, but still provides sufficient data to analyse use of each substance and compare this with 1998.

In the decade since the 1998 study was carried out, a raft of legislation has come into force aimed at reducing tobacco use in the UK: cigarette advertising banned on billboards and in press and media (2003), restrictions on advertising at the point of sale (2004), smoking banned in enclosed areas (2006-2007) and it became illegal to sell tobacco products to anyone under the age of 18 (2007). ${ }^{2}$ Whether this legislation has caused the reduction in tobacco smoking reported among dental undergraduates between 1998 and 2008, being significant among females, is not known. Reductions have been seen in the general population and among VDPs. While this is encouraging and hopefully the downward trend will continue, the fact that tobacco smoking has become increasingly stigmatised over the past decade may increase the likelihood of people under-reporting use ${ }^{2}$ and therefore reducing the reliability of trend data.

A significant reduction in the number of dental undergraduates drinking alcohol in 2008 compared to 1998 was reported. The most likely explanation for this is the increase in ethnic minority undergraduates, who as mentioned above are less likely to drink than their white colleagues. Due to the confidential nature of the questionnaire, with ethnic origin information not requested, this is only an assumption and further research is required.

Of those dental undergraduates drinking, a reduction was seen in the average number of units consumed in a week, with significantly fewer males drinking at levels of increased risk. However, there was a significant increase in the number of males reporting binge drinking. This would suggest that although fewer units were consumed over a week, drinking is being concentrated into a session and further research is advisable to see if these were Friday and Saturday nights, suggesting undergraduates are bingeing on these days to avoid attending next day clinical sessions with a hangover.

An increase in binge drinking has also been seen in the general population and among VDPs. The change in the licensing laws which came into force in 2005, allowing 24 hour drinking, ${ }^{21}$ may be one explanation for this increase, with the time available to drink on a night out now longer.

In 2008 female undergraduates were significantly less like likely to overestimate the number of units of alcohol they could safely consume in a week compared to those in 1998. This increase in knowledge of safe weekly maximums could be due to the government's recent advertising 
campaign to raise awareness of the number of units of alcohol drinks contain ${ }^{22}$ and/ or due to the lead author's drug and alcohol awareness lectures, given to all dental undergraduates at the university surveyed. While there was also an increase in knowledge among male undergraduates it was not significant. This needs further investigation to find a method of better educating male undergraduates.

The government recommends that "men should not regularly drink more than 3-4 units of alcohol a day and women should not regularly drink more than 2-3 units a day. "Regularly" means drinking every day or most days of the week. You should also take a break for 48 hours after a heavy session to let your body recover.'23 These guidelines are prone to misinterpretation as allowing 28 units to be consumed by males per week (4 units a day for 7 days) and 21 units for females (3 units a day for 7 days). Also they imply that 'heavy' drinking sessions are acceptable as long as no drinking occurs for 48 hours afterwards. This would appear to condone binge drinking as long as it is followed by 48 hours of abstinence. Figures quoted for sensible weekly alcohol consumptions levels (0-21 units for men, 0-14 units for women) used in this paper are those advised by the British Medical Association. ${ }^{24}$

In 2008 there were significantly fewer undergraduates of both sexes reporting cannabis use while at university and before entry compared to 1998. Of those reporting use, significantly fewer were regular users at any point as an undergraduate in 2008 compared to 1998. Similar reductions were seen in the general population over the decade, but little change was seen among VDPs in 2005 compared to 2000. The authors plan to repeat the VDP study in 2010 which will allow a more up-todate view.

In January 2004 cannabis was reclassified from a Class B to a Class C drug. However, in January 2009 the government reclassified cannabis from Class $\mathrm{C}$ back to Class B. ${ }^{25}$ This went against the recommendation of the government's expert independent advisory group the Advisory Council on the Misuse of Drugs (ACMD). The ACMD were asked to review cannabis classification by the government due to concerns regarding stronger strains of cannabis in circulation called 'skunk'. The
ACMD concluded that cannabis should not be re-classified and should remain a Class C drug. ${ }^{26}$

The ACMD have recently advised downgrading ecstasy from Class A to Class $\mathrm{B},{ }^{27}$ but the government has decided to maintain its Class A status. This is disappointing as the government has reported a desire for drugs policy to be based on the evidence of harmfulness to the individuals and society.

Over the decade since the 1998 study was carried out, as well as re-classification of cannabis, a change in the classification of magic mushrooms has occurred. Following the introduction of the Drugs Act 2005, raw magic mushrooms were classified as a Class A drug. Before this change in the law, only prepared (such as dried or stewed) magic mushrooms were classified as Class A drugs. ${ }^{28}$

Among the dental undergraduates at the one university surveyed there were significant changes in the prevalence of cannabis, amphetamine and amyl nitrate use between 1998 and 2008. A significant increase in the use of amyl nitrite by female but not male dental undergraduates in 2008 compared to 1998 was reported. Amyl nitrite is chemically related to laughing gas and is not controlled under the misuse of drugs act. It is easily available from sex shops, joke shops and at dance events. Amyl nitrite can be used to reduce inhibition, produce stimulation while dancing, enhance sexual activity and has traditionally been associated with the gay community due to its anal sphincter relaxing effect. ${ }^{13}$ Why an increase in use among female but not male dental undergraduates had occurred is not known and requires further investigation.

Class A drug use in the general population has seen a slight but not significant increase since 1998, mainly due to the increase in the use of cocaine powder. Cocaine use has now become normalised in the general population with prices falling from approximately $£ 70$ per gram in 2000 to approximately $£ 42$ per gram in 2008. ${ }^{29}$

A strong association between illicit drug use and dental undergraduates reporting tobacco and alcohol use was found. A similar association was found in the authors' previous studies. This would suggest that targeted advice should be given to those who use tobacco and alcohol.

Given the successful administration of the questionnaire used in this study it would be possible to repeat its administration at all UK university dental departments if funding and approval could be obtained. This would allow a more accurate measure of substance use among dental undergraduates and could be used to identify schools with outlier results giving cause for concern. Expanding this study to a wider dental undergraduate population would also allow the trialling of different harm reduction and primary prevention programs to allow a robust comparison of which is most effective. The most effective could then be introduced throughout the UK's university dental departments.

\section{CONCLUSIONS}

Dental undergraduates at one English university in 2008 when compared to those in 1998 are reported to be significantly less likely to drink alcohol, use cannabis and amphetamines. If female, they are significantly less likely to smoke tobacco and overestimate the number of units of alcohol they can safely consume in a week, but more likely to use amyl nitrate. If male, those who drink alcohol are significantly less likely to drink at a level of increased risk, but more likely to binge drink.

The authors would like to acknowledge the Alcohol Education and Research Council, whose funding made this study possible. The authors would also like to thank the undergraduates who took part in this study.

1. Underwood B, Fox K. A survey of alcohol and drug use among UK based dental undergraduates. Br Dent J 2000; 189: 314-317.

2. Robinson S, Lader D. General household survey 2007. Smoking and drinking among adults, 2007. London: Office for National Statistics, 2007. http://www.statistics.gov. uk/downloads/theme_compendia/GHS07/ GHSSmokingandDrinkingAmongAdults2007.pdf (accessed 18 February 2009)

3. Goddard E. General household survey 2006 Smoking and drinking among adults, 2006. London: Office for National Statistics, 2006. http://www. statistics.gov.uk/Statbase/Product.asp?vlnk=5756 (accessed 18 February 2009).

4. Goddard E. Drinking: adults' behaviour and knowledge in 2007. London: Office for National Statistics, 2007. Omnibus survey report no. 34. http:// www.statistics.gov.uk/downloads/theme_health/ Drinking_2007.pdf (accessed 18 February 2009).

5. McAlaney J, McMahon J. Establishing rates of binge drinking in the UK: anomalies in the data. Alcohol Alcohol 2006; 41: 355-357.

6. Institute of Alcohol Studies. Binge drinking: nature, prevalence and cause. St Ives: Institute of Alcohol Studies, 2007. ISA Factsheet.

7. Gill J S. Reported levels of alcohol consumption and binge drinking within the UK undergraduate 
student population over the last 25 years. Alcohol Alcohol 2002; 37: 109-120.

8. Hoare J, Flatley J. Drugs misuse declared: findings from the 2007/8 British crime survey. England and Wales. London: Home Office Statistics, 2008.

9. COPDEND/DVT. What's new in dental vocationa training? Webpage. http://www.copdend.org.uk/dvt/ page.php? $1=1142419632 \&|2=\varepsilon t| 3=\varepsilon t \mid 4=$ Link\&tre $f=1160727529$ (accessed 18 February 2009).

10. Underwood B, Fox K, Nixon P J. Alcohol and drug use among vocational dental practitioners. Br Dent J 2003; 195: 265-268.

11. Underwood B, Hackshaw A, Fox K. Smoking, alcohol and drug use among vocational dental practitioners in 2000 and 2005. Br Dent J 2007; 203: 701-705.

12. Barber M W, Fairclough A. A comparison of alcoho and drug use among dental undergraduates and a group of non-medical, professional undergraduates. Br Dent J 2006; 201: 581-584.

13. Newbury-Birch D, Lowry R J, Kalmali F. The changing patterns of drinking, illicit drug use, stress, anxiety and depression in dental students in a UK dental school: a longitudinal study. Br Dent J 2002; 192: 646-649.

14. Anonymous. Steroid use 'on par with heroin'. BBC News online 2007 May 20. http://news.bbc.co.uk/1/ hi/health/6673449.stm (accessed 5 March 2009).

15. Frank. A-Z of drugs - poppers.

http://www.talktofrank.com/drugs.aspx?id=198 (accessed 5 March 2009).

16. Frank. A-Z of drugs - gases, glues and aerosols. The law. http://www.talktofrank.com/drugs. aspx?id=182\#law (accessed 5 March 2009)

17. File S E, Mabbutt PS, Shaffer J. Alcohol consumption and lifestyle in medical students. J Psychopharmacol 1994; 8: 22-26.

18. Webb E, Ashton C H, Kelly P, Kamali F. Alcohol and drug use in UK university students. Lancet 1996; 348: 922-925.

19. National Statistics Online. Ethnicity and identity. Smoking and drinking. http://www.statistics.gov.uk/ cci/nugget.asp?id=466 (accessed 18 February 2009).

20. Personal correspondence with university surveyed UCAS data.

21. Department for Culture, Media and Sport. Licensing act 2003 explained. http://www.culture.gov.uk/4051. aspx (accessed 5 March 2009).

22. Department of Health. Alcohol units campaign. London: Department of Health, 2009. Press release. http://www.dh.gov.uk/en/News/Recentstories/ DH_084904 (accessed 5 March 2009).

23. Department of Health. Alcohol advice webpage.
http://www.dh.gov.uk/en/Publichealth/ Healthimprovement/Alcoholmisuse/DH_085385 (accessed 5 March 2009).

24. British Medical Association. Alcohol: guidelines on sensible drinking. London: BMA, 1995

25. Home Office. Cannabis webpage. http://www.homeoffice.gov.uk/drugs/drugs-law/ cannabis-reclassification/ (accessed 5 March 2009).

26. Advisory Council on the Misuse of Drugs. Cannabis: classification and public health. London: Home Office, 2008. http://www.drugs.homeoffice.gov. uk/publication-search/acmd/acmd-cannabisreport-20082835.pdf?view=Binary (accessed 13 January 2010).

27. Advisory Council on the Misuse of Drugs. MDMA ('ecstasy'): a review of its harms and classification under the misuse of drugs act 1971. London: Home Office, 2008. http://www.drugs.homeoffice.gov. uk/publication-search/acmd/mdma-report2835. pdf?view=Binary (accessed 13 January 2010).

28. Home Office. Drugs act 2005. http://drugs.homeoffice.gov.uk/drugs-laws/ drug-act-2005/ (accessed 5 March 2009).

29. Home Office. Frank action update. Cocaine explained. http://drugs.homeoffice.gov.uk/ pdfs/603190.pdf (accessed 5 March 2009). 